\title{
Erratum to: Will climate change increase or decrease suicide rates? The differing effects of geographical, seasonal, and irregular variation in temperature on suicide incidence
}

\author{
Matt N. Williams ${ }^{1} \cdot$ Stephen R. Hill $^{1} \cdot$ John Spicer $^{1}$
}

Published online: 30 November 2015

(C) Springer Science+Business Media Dordrecht 2015

\section{Erratum to: Climatic Change (2015) 130:519-528 \\ DOI 10.1007/s10584-015-1371-9}

The third sentence of the second paragraph of section 3.2 should read (correction in bold):

$$
\begin{aligned}
& \text { The resulting estimated effect of seasonal variation in temperature was tiny, } \\
& \hat{\beta}=4.63 \times 10^{-4}, p=.881,95 \% \mathrm{CI}[-0.006,0.007] \text {. }
\end{aligned}
$$

Furthermore, Tables 2, 3 and 4 in the Electronic Supplementary Material (ESM) were numbered incorrectly. The corrected ESM is included with the online version of this Erratum.

The online version of the original article can be found at http://dx.doi.org/10.1007/s10584-015-1371-9.

Electronic supplementary material The online version of this article (doi:10.1007/s10584-015-1571-3) contains supplementary material, which is available to authorized users.

Matt N. Williams

mattnwilliams@gmail.com

1 School of Psychology, Massey University, Private Bag 102904, Auckland 0745, New Zealand 